\title{
Treatment of Spent Nuclear Fuel for Separation, Immobilization and Disposal of Heat Generating High Level Fission Products, Caesium and Strontium
}

\author{
Md Akhlak Bin Aziz ${ }^{1}$, Afrin Ahsan ${ }^{1}$, Md Monsurul Islam Khan ${ }^{2}$, Dr. Zahid Hasan Mahmood ${ }^{3}$ \\ ${ }^{1}$ Military Institute of Science and Technology \\ ${ }^{2}$ Indiana University Purdue University Indianapolis, Email: monsurulbuet11@yahoo.com \\ ${ }^{3}$ University of Dhaka, Email: zahid@univdhaka.edu.bd
}

\begin{abstract}
Separation of heat generating, high level fission product caesium and strontium from spent nuclear fuel boosts the capacity of waste repositories by as much as fifty times. For efficient use of already scarce repositories, separation of such fission products is mandatory. Separations of caesium and strontium using Chlorinated Cobalt Dicarbollide (CCD), PEG (Polyethylene Glycol), UNEX process and by Calixarenes or Fission Product Extraction Process (FPEX) were discussed. The UNEX method was then proposed as the most feasible method option. Following separation, nuclear waste immobilization techniques for such high-level fission product were discussed. The techniques included usage of concrete, glass and synthetic rock. Among them synthetic rock was identified as the most suitable one for immobilization of high-level nuclear waste. Finally, a safe disposal system with necessary required geology was shown for safe disposal of the waste.
\end{abstract}

Keywords: Nuclear Spent Fuel, Fission Product, UNEX process, Waste Immobilization

\section{Introduction}

With increasing energy demand, production of zero carbon nuclear energy is necessary to protect the environment. The abundance of uranium and that even a very small amount of uranium can supply a large amount of energy can only strengthen this stance ${ }^{[1]}$. The only problem, dealing with nuclear waste, particularly spent nuclear fuel, is also being mitigated by modern separation technologies, immobilisation methods and disposal systems. These new technologies are results of extensive research around the world like the advanced fuel cycle initiative funded by US department of energy directed towards the separation of constituents that add to the heat load at the high level waste (HLW) repositories ${ }^{[2]}$.

\section{Nuclear Fuel Cycle and Processing of Spent Fuel}

The nuclear fuel cycle entails several steps starting from uranium extraction, conversion to nuclear fuel, treatment and finally disposal of either spent fuel or wastes generated from reprocessing. The initial steps of mining and milling, conversion, enrichment and fuel fabrication make up the front end of the cycle. The back end comprises of: temporary storage and disposal for an open cycle; temporary storage, reprocessing, recycling and then disposal for a closed cycle.

\subsection{Reprocessing and Its Advantages}

After fuel burn up, the fuel assemblies are taken out and stored temporarily before being disposed or reprocessed. Spent fuel contains $95-96 \%$ uranium, $1 \%$ plutonium, $0.1 \%$ other actinides and $3-4 \%$ fission products ${ }^{[3]}$. Reprocessing is the recovery of the fissile materials from the spent fuel and separation of different materials for better disposal ${ }^{[4]}$. In many countries like UK, Japan etc. the spent nuclear fuel is reprocessed while in others like USA and Canada, the spent nuclear fuel is temporarily stored before being disposed directly. The historical and projected amount of spent fuel discharged, reprocessed and stored is shown below.

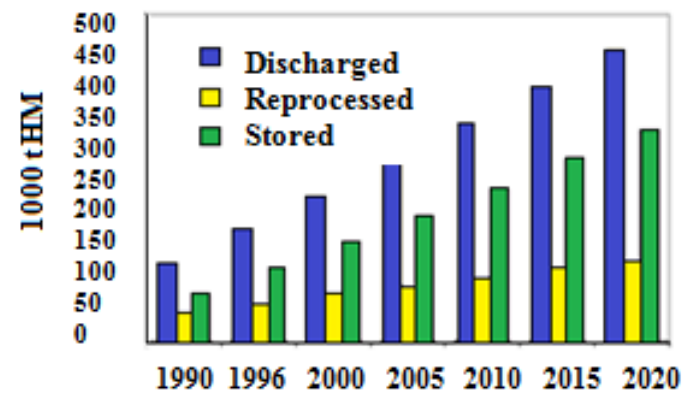

Fig 1: Historical amount of spent fuel stored and discharged ${ }^{[3]}$.

Reprocessing allows recycling of nuclear fuel and leads to safeguarding the uranium resources. Recycling means a part of the spent fuel is inserted back to the fuel cycle and thus closing the cycle, adding $25-30 \%$ more energy from the original uranium ${ }^{[5,6,7]}$. Reprocessing can contribute to the protection of uranium resources and energy security to a great extent. After reprocessing, since a majority of the spent fuel is inserted back to the fuel cycle, the volume of waste that must be meticulously handled for transport and disposal is reduced by

\footnotetext{
Corresponding Author: Md Akhlak B. Aziz,

E-mail: akhlak69@gmail.com
} 
one-fifth ${ }^{[5,6,7]}$.Reduction of waste volume also means the adverse effects on the environment directly and indirectly due to the waste is also minimized. On the other hand, with more reprocessing of the spent fuel, less uranium will be required from mining, reducing the wastes and carbon footprints.

\subsection{Spent Nuclear Fuel}

For reprocessing, the cladding material is removed first followed by dissolution in nitric acid. Then chemical extraction is used to extract uranium and plutonium leaving behind dissolved fission products, actinides, transuranic elements etc. The exact composition of the spent nuclear fuel depends on the reactor type and the conditions under which it is operated but the difference in the fission products will be very little ${ }^{[8,9]}$.

Fission product fraction is dependent on the fuel burn ups with greater amounts produced in higher burn up fuels. The US inventory of spent nuclear fuel consists of $2-5 w t \%$ fission products depending on the fuel burn up ${ }^{[10]}$. The fission products are predominantly centred around two mass fractions of 90-100 in the light fraction and 135-145 in the heavy fraction ${ }^{[10]}$. For easier handling, the fission products are classified according to their chemical and radiological properties.

\section{Importance of Separating $\mathrm{Cs} / \mathrm{Sr}$ from the Spent Fuel}

Treating irradiated fuel chemically has been going on for more than half a century [11]. The most commonly applied reprocessing technique begins with aqueous dissolution of the spent fuel followed by liquid-liquid extraction to separate the uranium and plutonium from radioactive fission and activation products. But the heat generating fission products limit the amount of materials that can be disposed in spent nuclear fuel repositories. The radiation field in these repositories is a function of both short-term heat-generating elements such as caesium (half life 30 years) and strontium (half life 29 years) and the long-term heat generating elements such as plutonium and americium. These along with the separation of actinides allow a significant increase in drift loading in the repository; as much as fifty times greater than for direct disposal ${ }^{[12]}$. To fully utilize the space of the repositories, it is therefore compulsory to separate the heat generating elements like caesium and strontium from the fission products.

\subsection{Available Methods for Separation}

Efficient treatment of caesium and strontium requires the minimization of the number of separation processes required. Implementing a separation technique that can simultaneously separate caesium and strontium from spent nuclear fuel and allow their management as a single product can effectively minimize the number of separation steps required. Simultaneous extraction of caesium and strontium reduces the overall complexity and the costs and more importantly provides scopes for management as a single waste form. A number of ion exchange/extraction chromatography and solvent extraction methods has been developed to separate caesium and strontium but effective acid side separation of strontium by ion exchange method is not identified ${ }^{[13,14]}$. Useful methods for caesium and strontium separation have been discussed below and the most appropriate one has been proposed.

\subsubsection{Using Chlorinated Cobalt Dicarbollide (CCD)/PEG (Polyethylene Glycol):}

The usefulness of CCD as caesium extractant was first identified by Rais and Kyrs in 1976 at the Nuclear Research Institute of Czechoslovakia ${ }^{[15]}$. They also identified that adding PEG to CCD dissolved in nitrobenzene would also allow extraction of strontium. Researchers of Khlopin Radium Institute (KRI) Russia developed a method for combined extraction of $\mathrm{Cs} / \mathrm{Sr}$, which was later applied on an industrial scale. Separation efficiencies of $99.992 \%$ and $97.5 \%$ were achieved for strontium and caesium respectively ${ }^{[16]}$. Although it was successful in Russia, tests in USA showed that nitrobenzene and nitroaromatic diluents had environmental, health and safety issues and was deemed unacceptable ${ }^{[16]}$. To solve the issues, further research later identified phenylpolyfluoroalkylsulfones as promising diluents that allowed simultaneous extraction of caesium, strontium and also actinides. The hydrazine based stripping agent was replaced by guanidine carbonate and diethylenetriaminepentaacetic acid (DTPA) that showed satisfactory results ${ }^{[16]}$. The process was named Universal extraction (UNEX). The process was thoroughly tested and successfully demonstrated using a simulated waste feed for 70 hours with centrifugal contractors in continuous operation ${ }^{[17]}$. With all the convincing test results it is now widely used on a production scale.

\subsubsection{Using Calixarenes/ Fission Product Extraction Process (FPEX):}

FPEX was developed based on a combined solvent containing two extractants. Strontium extraction was based on di-cyclohexano 18-crown-6 extractant dissolved in 1-octanol developed in the 1990s in Argonne National Laboratory (ANL) and was called SREX process ${ }^{[18]}$. The extraction used for caesium was caustic side solvent extraction (CSSX) utilizing the solvent Calix ${ }^{[19]}$ arene-bis(tertoctylbenzo-crown6) (BOBCalixC6) combined with a phase modifier-1. (2,2,3,3- tetrafluoropropoxy)-3-(4-sec-butylphenoxy)- 
2-propanol (Cs-7SB) in a branched aliphatic hydrocarbon diluent developed in the Oak Ridge National Laboratory ${ }^{[20]}$. Combined solvents were initially tested at the Idaho National Engineering and Environmental Laboratory. Results showed that both caesium and strontium could be effectively extracted from $1 \mathrm{M}$ nitric acid ${ }^{[21]}$. The advantage of calixarenes over CCD is caesium can be easily stripped off them using water or nitric acid. But calixarene is a very expensive extractant. Although this method seems promising, it requires a lot more testing before being applied commercially.

\subsection{Proposed Method of Separation}

The UNEX method is the most viable and preferred option that can be utilized for an efficient separation of the $\mathrm{Cs} / \mathrm{Sr}$ fission products from the spent nuclear fuel. This method has been widely tested and successfully demonstrated as mentioned earlier. It is also widely applied for industrial separation. Excellent removal efficiencies of 99 to $99.99 \%$ are also achievable with a properly designed flow sheet ${ }^{[22]}$. Unlike other methods, actinides can also be separated using CCD/PEG solvent. UNEX requires less number of process steps and hence it is simpler and cheaper when compared to ion exchange method where caesium and strontium need to be separately extracted. Since UNEX uses less expensive extractant, it is also cheaper than FPEX process that also separates $\mathrm{Cs} / \mathrm{Sr}$ simultaneously ${ }^{[16]}$. Moreover, FPEX is not industrially used like UNEX and requires more testing. Radiation and chemical stability of CCD and PEG is also very good ${ }^{[23]}$.Phenyl-polyfluoro-alkylsulfones diluents used in the UNEX process are chemically harmless, have excellent radiation stability and surpass typical PUREX solvent explosion and fire safety indices $^{[21,19,16]}$. After separation of caesium and strontium along with the actinides using the most suitable method, the waste must be properly immobilized before disposal.

\section{Immobilization of Waste}

Radioactive waste materials are immobilized in glass, ceramic, concrete etc. to make it solid, immobile, stable and durable so that it can be easily stored temporarily and then permanently disposed with safety so that the materials do not get back to the biosphere. Immobilization is achieved by incorporation of the waste elements within the host lattice on an atomic scale or by encapsulation of the waste within an inert material. Different types of immobilization are discussed below.

\subsection{Concrete}

Concrete has only been used to immobilize low and intermediate level waste ${ }^{[24]}$. Inactive constituents of waste streams may prevent sufficient hardening of the concrete. Due to high levels of radioactivity, radiolysis or breakdown of water or hydroxyl groups may lead to release of hydrogen which can be very dangerous ${ }^{[25]}$. Concrete's micro porous and alkaline nature causes precipitation of alkaline-insoluble waste species that are ultimately leached out. Concrete can be used only for some specific waste streams and most of the research on it slowed down after the emergence of a better substitute borosilicate glass. Although concrete is inexpensive, readily available and does not require high temperature processing, it is not widely used or preferred for immobilization of HLW due to its disadvantages.

\subsection{Glass}

Immobilization of HLW using borosilicate glass is a well-established process used in many countries ${ }^{[25]}$. Initially $30 \mathrm{wt} \% \mathrm{HLW}$ incorporation was proposed. But with $30 \mathrm{wt} \%$ loading, heat release causes centreline temperatures to reach $300^{\circ} \mathrm{C}$. If glass comes in contact with water at $300^{\circ} \mathrm{C}$, the glass will disintegrate within few days ${ }^{[26]}$. Leaching of glass starts above $100^{\circ} \mathrm{C}$. Therefore, maximum loading in glass must be reduced to only $10 \mathrm{wt} \%$ and must be intermediately stored for decades until temperature falls below $100^{\circ} \mathrm{C}$.

\subsection{Synthetic Rock (SYNROC)}

Synthetic rock (SYNROC), a titanate ceramic used to immobilize HLW and composed of rutile $\mathrm{TiO}_{2}$, 'hollandite' $\mathrm{Ba}(\mathrm{A} 1, \mathrm{Ti}) \mathrm{Ti}_{6} \mathrm{O}_{16}$, zirconolite $\mathrm{CaZrTi}{ }_{2} \mathrm{OT}$, and perovskiteCaTiO, is highly resistant to leaching, particularly at temperatures greater than $100^{\circ} \mathrm{C}$. In SYNROC hollandite, small cations $\left(\mathrm{Ti}^{4+}, \mathrm{Ti}^{3+}\right.$, and $\mathrm{A} 1^{3+}$ ) are octahedrally arranged surrounded by eight oxygen anions at corners of a cube. This excellent cage like structure hinders migration of large cations like $\mathrm{Ba}^{2+}$ and $\mathrm{Cs}^{2+}$ allowing excellent resistant of SYNROC to groundwater. Moreover, SYNROC can also be increased from $10 \mathrm{wt} \%$ to $20 \mathrm{wt} \%$ without compromising its performance and flexibility ${ }^{[27]}$.

\subsection{Proposed Method of Immobilization}

Using concrete may leave the risk of radiolysis and release of combustible hydrogen gas. Moreover, concrete was used for only intermediate and low level waste. As a result, concrete is not suitable for HLW immobilization. Glasses crystallize if heated at high temperatures for sufficient periods. This crystallization is usually uncontrolled by nucleation of large crystals from external surfaces. This puts unwanted stress, leading to cracking and ultimately significant amounts of leaching ${ }^{[6]}$. There is no such problem with SYNROC. 
When compared to borosilicate glass, durability of SYNROC is less affected by leachant flow rate ${ }^{[25]}$. Leachant $\mathrm{pH}$ also has a significant effect on the leach rate of glass. HLW glasses have high alkali oxide content that gives enhanced leach rates for acidic solutions. Unlike borosilicate glass, $\mathrm{pH}$ variation does not affect the durability of SYNROC.

Additionally, SYNROC can incorporate almost all cations of different charges into its crystalline phases and can adjust spontaneously to variations of the waste composition ${ }^{[26]}$. The perovskite family of structure of SYNROC can incorporate strontium, rare earths and trivalent actinides like $\mathrm{Pu}^{3+}$. Similarly other family of structures of SYNROC can hold many other elements.

Each alpha decay from the high level waste releases a helium nucleus that is absorbed by the glass. Number of helium nucleus absorbed is proportional to the alpha dose and higher doses may lead to swelling and cracking. Helium bubbles formed provides nucleation centres creating uncontrolled crystallization, giving extra stress on the structure and thus leading to cracking and leaching. Solubility of helium in borosilicate glass is $1.5 \times 10^{22}$ atoms $\mathrm{m}$ ${ }^{3[25]}$. Alpha decay in SYNROC is confined within the perovskite and zirconlire phases. The zirconlite phase alone has a solubility of helium around $4.4 \times 10^{24} \mathrm{~m}^{-3}$ in SYNROC, which is around 300 times greater than borosilicate glass ${ }^{[25]}$. These properties make SYNROC extremely durable with high radiation resistance. Evidence also supports that SYNROC survived millions of years in a wide range of geological environments ${ }^{[26]}$. As a result, SYNROC is the preferred method of immobilization due to its superior mechanical properties like high durability, high thermal stability, ability to accommodate high concentrations of high level wastes etc.

\section{Geological Disposal Facility}

The ideal geology to build a repository for disposing high level waste containing cesium and strontium would be a one with dry hard rock that had no water or rainfall in the past several thousand years and neither will it have in the next; like the Andrews, Texas, USA WCS repository ${ }^{[4]}$. Since formation of a repository as in WCS Texas is very rare, the types most preferred are salt, clay and hard rock (granite or basalt). Salt because salt deposits throughout the world have remained stable for millions of years; clay because it is highly impermeable to water and granite or basalt because their formations are found in very stable geological environments.

Incorporation of the HLW in SYNROC is followed by putting it inside metallic canisters composed of $\mathrm{Ti}$ and $\mathrm{Pb}$. Although SYNROC is itself highly leach resistant and suitable for direct disposal, canisters of $\mathrm{Ti}$ and $\mathrm{Pb}$ are chosen to be extra cautious as they are highly resistant to corrosion by groundwater. Bentonite is a material that greatly obstructs access of groundwater to the waste and fixes any radioactive element that gets dissolved in the water. As a conservative approach, the cannisters can be surrounded by bentonite over packs before disposing.

After finding a suitable geology for the disposal of HLW SYNROC canisters, deep boreholes can be drilled according to the design shown by Ringwood $[26]$

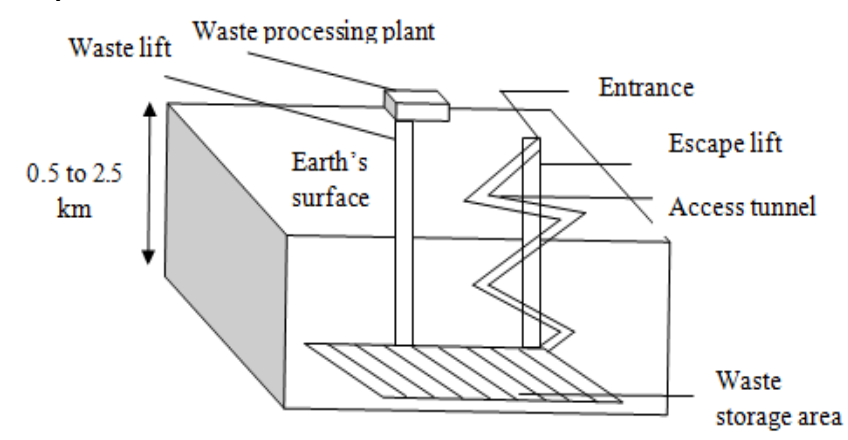

Fig 2: Deep disposal mechanism of high-level nuclear waste ${ }^{[28]}$.

A drilled hole will absorb $1 \mathrm{~m}$ diameter canisters upto to $2.5 \mathrm{~km}$. Such a hole will be able to absorb waste produced by eighty $1000 \mathrm{MW}$ nuclear power stations in a year ${ }^{[26]}$. Crystalline rocks formations are dry and highly impermeable to water at depths greater than 1 $\mathrm{km}$ and the geological barrier is very stable. This minimizes the chances of access by groundwater. Drilling causes least damage to the rock system and the holes can be easily sealed.

Distribution of HLW in a densely packed horizontal array puts lot of thermal stress that may lead to fracturing of the host rock allowing groundwater access. Such a problem can also be avoided in such a deep-drilled repository using proper package density and using materials like SYNROC that is insensitive to temperature gradient. Since temperature increases by $20-30^{\circ} \mathrm{C}$ per kilometer below the earth's surface, glass is not suitable. Glass may disintegrate when comes in contact at high temperatures. In contrast SYNROC is perfectly suitable for such a deep-drilled repository, as in that way integrity of both the geological barrier and the immobilization barrier is retained and the system remains stable.

\section{Conclusion}

Separating the heat generating fission products caesium and strontium by UNEX method is the most efficient way of getting caesium and strontium out of the spent nuclear fuel. The method has been widely 
tested and is the best in terms of extraction efficiency of more than $99 \%$. Considering the possibility of simultaneous removal of caesium and strontium along with actinides, this method is highly cost effective as well. After removal, it was proposed to immobilize the fission products using SYNROC. Although SYNROC involves complex processing and is expensive in the short run, it is still recommended. This is because SYNROC is the safest form in the long run of several million years and very little or no extra precautionary measures must be taken which will ultimately make it cheaper. Finally the disposal strategy described will provide the maximum output at minimum costs. It just needs drilling deep holes that are very practical considering the latest technology available. It will leave the least amount of footprint, will be easy and fast and allow maximum amount of safe disposal with minimum efforts and space required.

\section{References}

1. The Independent, 2015. Nuclear power is the greenest option, say top scientists. [online] Available at: <http://www.independent.co.uk/news/science/n uclear-power-is-the-greenest-option-say-topscientists-9955997.html> [Accessed 6 January 2017].

2. Laidler, J. J. and Bresee, J. C. (2004). The U.S. Advanced Fuel Cycle Initiative:Development of Separation Technologies. Proc. Int. Cnf. for Advances for Nuclear FuelCycles, ATALANTE 2004, Nimes, France. Available at<http://www.iaea.org/inis/collection/NCLColle ctionStore/_Public/36/008/36008576.pdf> [Accessed 9 June, 2017].

3. IAEA. Storage and Disposal of Spent Fuel and High Level Radioactive Waste. [online]Available at:<http://www.iaea.org/About/Policy/GC/GC50 /GC50InfDocuments/English/gc50inf-3att5_en.pdf> [Accessed 10 November 2017].

4. WCS. Treatment and Storage. 2017. [online] Available at: $<$ http://www.wcstexas.com/facilities/treatmentand-storage/>[Accessed 6 November 2017].

5. World Nuclear Association, 2015. World Nuclear Power and Uranium Requirements. [online] Available at: <http://www.worldnuclear.org/info/Facts-and-Figures/WorldNuclear-Power-Reactors-and-UraniumRequirements/> [Accessed 5 January 2015].
6. World Nuclear Association, 2014. Uranium Mining Overview. [online] Available at: $<$ http://www.world-nuclear.org/info/NuclearFuel-Cycle/Mining-of-Uranium/Uranium-MiningOverview/> [Accessed 12 January 2017].

7. World Nuclear Association, 2014. The Nuclear Fuel Cycle. [online] Available at: $<$ http://www.world-nuclear.org/info/NuclearFuel-Cycle/Introduction/Nuclear-Fuel-CycleOverview/> [Accessed 5 January 2017].

8. International Atomic Energy Agency (Vienna), Design and operation of high level waste vitrification and storage facilities, Technical Reports Series No. 339 (IAEA, Vienna, 1992), Available at<http://wwwpub.iaea.org/books/IAEABooks/1443/Designand-Operation-of-High-Level-WasteVitrification-and-Storage-Facilities> [Accessed 12 June, 2017].

9. L. H. JOHNSON L. H. and D. W. SHOESMITH D. W., 1988. in "Radioactive waste forms for the future", edited by W. Lutze and R. C. Ewing (North-Holland, Amsterdam, 1988) pp. 635-98.

10. Collins E. D., Del G. D., Cul, Moyer B. A., 2011.Advanced reprocessing for fission product separation and exraaction, Oak Ridge National Laboratory, USA.

11. Choppin G. R., Khankhasayev M. K., Plendl H. S., 2002.Chemical Separations in Nuclear Waste Management, DOE/EM-0591, Battelle Press, Columbus $\mathrm{OH}$.

12. Wigeland, R. A., Bauer, T. H., Fanning, T. H., and Morris, E. E. (2004). Spent NuclearFuels Separation and Transmutation Criteria for Benefit to a Geologic Repository. Proc. of Waste Management '04, Tucson, AZ.

13. Alkaline-Side CSEX Solvent Suitable for Removing Cesium from Savannah River HighLevel Waste. Solvent Extraction and Ion Exchange, 18(6), 1079-1108.

14. Clearfield A., 2000.Inorganic Ion Exchangers, Past, Present, and Future, Solvent Extraction Ion Exchange, 18(4), 655-678.

15. Rais J., Selucky P., KyrĞ M., Extraction of Alkali-Metals into Nitrobenzene in Presence of Univalent Polyhedral Borate Anions, Journal of Inorganic Nuclear Chemistry, 38, 1376, 1976.

16. Todd T. A., Batcheller T. A., Law J. D., Herbst R. S., 2004. Cesium and Strontium Technologies Literature Review. 
17. Law J. D., 2002. Extended Flowsheet Testing of the Universal Extraction (UNEX) Process for the Simultaneous Separation of Cesium, Strontium and Actinides from Acidic Waste, Proceedings of the International Solvent Extraction Conference ISEC' 2002, Cape Town, South Africa, 1229-1234, 2002.

18. Horwitz E. P., Dietz M. L., Fisher D. E., 1990. Extraction of Strontium from Nitric Acid Solutions Using Dicyclohexano-18-Crown-6 and its Derivatives, Solvent Extraction and Ion Exchange, 8(4\&5), 557-572.

19. Law, J. D., Herbst, R. S., Peterman, D. R., Todd, T. A., Romanovskiy, V. N., Babain, V. A., Smirnov, I. V. (2005). Development of a Regenerable Strip Reagent for Treatment of Acidic, Radioactive Waste with Cobalt Dicarbollide Based Solvent Extraction Processes. Solvent Extraction and Ion Exchange, 23(1), 59-84.

20. Horwitz, E. P., Dietz, M. L., and Fisher, D. E. (1991). SREX: A New Process for theExtraction and Recovery of Strontium from Acidic Nuclear Waste Streams. Solvent Extraction and Ion Exchange, 9(1), 1-25.

21. Law J. D., Garn T. G., Herbst R. S., Meikrantz D. H., Peterman D. R., Riddle C. L., Todd T. A., Tripp J. L., 2006. Development of Cesium and Strontium Separation and Immobilization Technologies in Support of an Advanced Nuclear Fuel Cycle. WM'06 Conference, February 26 - March 2, 2006, Tucson, AZ.
22. Todd T. A., Batcheller T.A., Law J. D., Herbst R. S., 2004. Idaho National Engineering and Environmental Laboratory (INEEL): Cesium and Strontium Separation Technologies Literature Review.

23. Rais J., Plesek J., Selucky P., 1991Extraction of Cesium with Derivatives of CarboraneintoNitrobenzene, Journal of Radioanalytical and Nuclear Chemistry Ar., 148(2), 349-357.

24. FAIRHALL G., JOHNSON G. and NEWLAND K., 1996. inEuromat '96. Conference on Materials and Nuclear Power, Bournemouth, October 1996 (The Institute of Materials, London, 1996) pp. 197-204.

25. Donald I. W., Metcalfe B.L., Taylor R. N. J., Review the immobilization of high level radioactive wastes using ceramics and glasses.

26. Ringwood A.E., 1983. Disposal of high-level nuclear waste: a geological perspective. Hallimond lecture.

27. Ringwood A. E., 1978. Safe disposal of high levelnuclearreactor wastes: A new strategy. Austral. Nat. Univ. Press, Canberra, 64 pp.

28. Where is all the nuclear waste now?, Science ABC. [online] Availbale at:<https://www.scienceabc.com/innovation/sol ved-problem-nuclear-wastedisposal.html>[Accessed $15^{\text {th }}$ November, 2017] 